\title{
Effects of beetroot juice supplementation on intermittent high-intensity exercise efforts
}

\author{
Raúl Domínguez ${ }^{1 *}$, José Luis Maté-Muñoz ${ }^{1}$, Eduardo Cuenca², Pablo García-Fernández ${ }^{1}$, Fernando Mata-Ordoñez ${ }^{3}$, \\ María Carmen Lozano-Estevan ${ }^{1}$, Pablo Veiga-Herreros ${ }^{1}$, Sandro Fernandes da Silva ${ }^{4}$ and \\ Manuel Vicente Garnacho-Castaño ${ }^{2}$
}

\begin{abstract}
Beetroot juice contains high levels of inorganic nitrate $\left(\mathrm{NO}_{3}^{-}\right)$and its intake has proved effective at increasing blood nitric oxide (NO) concentrations. Given the effects of $\mathrm{NO}$ in promoting vasodilation and blood flow with beneficial impacts on muscle contraction, several studies have detected an ergogenic effect of beetroot juice supplementation on exercise efforts with high oxidative energy metabolism demands. However, only a scarce yet growing number of investigations have sought to assess the effects of this supplement on performance at high-intensity exercise. Here we review the few studies that have addressed this issue. The databases Dialnet, Elsevier, Medline, Pubmed and Web of Science were searched for articles in English, Portuguese and Spanish published from 2010 to March 31 to 2017 using the keywords: beet or beetroot or nitrate or nitrite and supplement or supplementation or nutrition or "sport nutrition" and exercise or sport or "physical activity" or effort or athlete. Nine articles fulfilling the inclusion criteria were identified. Results indicate that beetroot juice given as a single dose or over a few days may improve performance at intermittent, high-intensity efforts with short rest periods. The improvements observed were attributed to faster phosphocreatine resynthesis which could delay its depletion during repetitive exercise efforts. In addition, beetroot juice supplementation could improve muscle power output via a mechanism involving a faster muscle shortening velocity. The findings of some studies also suggested improved indicators of muscular fatigue, though the mechanism involved in this effect remains unclear.
\end{abstract}

Keywords: Beet, Ergogenic aids, Exercise, Sport supplement

\section{Background}

Because of the increase in competitive equality in high level sport, a $0.6 \%$ performance improvement is today considered sufficient to make a difference [1]. In this setting of high competition, athletes often look to nutritional supplements to boost their performance [2]. However, most statements about the potential effects on sport performance or health that appear on the labels of many products are not backed by clear scientific evidence [2]. Because of this, institutions such as the Australian Institute of Sport (AIS) have created a system to classify supplements according to their effects on performance based on confirmed scientific evidence [3]. Thus, dietary supplements assigned to class A

\footnotetext{
*Correspondence: rdomiher@uax.es

${ }^{1}$ Physical Activity and Sport Sciences, College of Health Sciences, Alfonso X El Sabio University, Madrid, Spain

Full list of author information is available at the end of the article
}

have been proven with a high level of evidence to improve exercise performance in certain modalities when taken in appropriate amounts. The only substances in this class are $\beta$-alanine, sodium bicarbonate, caffeine, creatine and beetroot juice [4]. However, it is thought that the effect of a given supplement on performance besides the recommended dose may be specific to each sport's modality [5] This, in turn, will depend on the energy and/or mechanical requirements of each form of exercise such that some supplements will have an ergogenic effect on some types of exercise efforts and have no effects on other types.

The relationship between exercise intensity and time to exhaustion is hyperbolic [6] as it is directly linked to the prevailing energy producing systems during exercise [7]. Thus, depending on their bioenergetics, the different exercise efforts can be classified according to exercise duration. This means we can differentiate between explosive efforts, 
high-intensity efforts and endurance-intensive efforts [8]. Explosive efforts are those lasting under $6 \mathrm{~s}$ in which the main energy metabolism pathway is the high-energy phosphagen system and there is some participation also of glycolysis $[9,10]$, which gradually contributes more energy until $50 \%$ at $6 \mathrm{~s}$ [9]. High-intensity efforts are those of duration longer than $6 \mathrm{~s}$ and shorter than $1 \mathrm{~min}$ [11]. These efforts are characterized by a major contribution of glycolytic metabolism and smaller contribution of highenergy phosphagens and oxidative phosphorylation [8]. Finally, intensive endurance efforts are those lasting longer than $60 \mathrm{~s}$ and whose main energy producing system is oxidative phosphorylation [8].

Beetroot juice is used as a supplement because it may serve as a precursor of nitric oxide (NO) [12]. The mechanism of NO synthesis is thought to be via the catabolism of arginine by the enzyme NO synthase [13]. Effectively, arginine supplementation has been shown to increase NO levels [14]. An alternative mechanism of NO genesis is mediated by inorganic nitrate $\left(\mathrm{NO}_{3}^{-}\right)$. This means that the high amounts of $\mathrm{NO}_{3}^{-}$present in beetroot juice are able to increase $\mathrm{NO}$ levels in the organism.

In the mouth, some $25 \%$ of dietary $\mathrm{NO}_{3}^{-}$is reduced by $\mathrm{NO}_{3}^{-}$reductase produced by microorganisms [15] to nitrite $\left(\mathrm{NO}_{2}^{-}\right)$[16]. This $\mathrm{NO}_{2}^{-}$is then partially reduced to NO through the actions of stomach acids which is later absorbed in the gut [17]. Some of this $\mathrm{NO}_{2}^{-}$enters the bloodstream, and, in conditions of low oxygen levels, will be converted into NO [18] (Fig. 1).

Nitrous oxide has numerous physiological functions including haemodynamic and metabolic actions [19, 20]. Mediated by guanylyl cyclase [21], NO has an effect on smooth muscle fibres causing blood vessel dilation [22] This vasodilation effect increases blood flow to muscle fibres [23] promoting gas exchange [24]. NO also induces gene expression [25], enhancing biogenesis [26] and mitochondrial efficiency [27]. All these effects can favour an oxidative energy metabolism. In effect, though not all [2831], numerous investigations have noted that beetroot juice supplementation boosts performance in exercise modalities involving intensive endurance efforts in which the dominant type of energy metabolism is oxidative [24, 27, 32-45].

To date, several reviews of the literature have assessed the effects of beetroot juice supplements on physical exercise [12, 46-49]. In addition, given that NO can potentiate the factors that limit performance when executing actions in which the predominant metabolism is oxidative, two recent reviews have explored the positive effects of this form of supplementation on endurance exercise [50,51]. Thus, the different studies showed that beetroot juice supplementation was effective at: lowering $\mathrm{VO}_{2}$ by $-6 \%$ during a swimming test conducted at an intensity equivalent to the

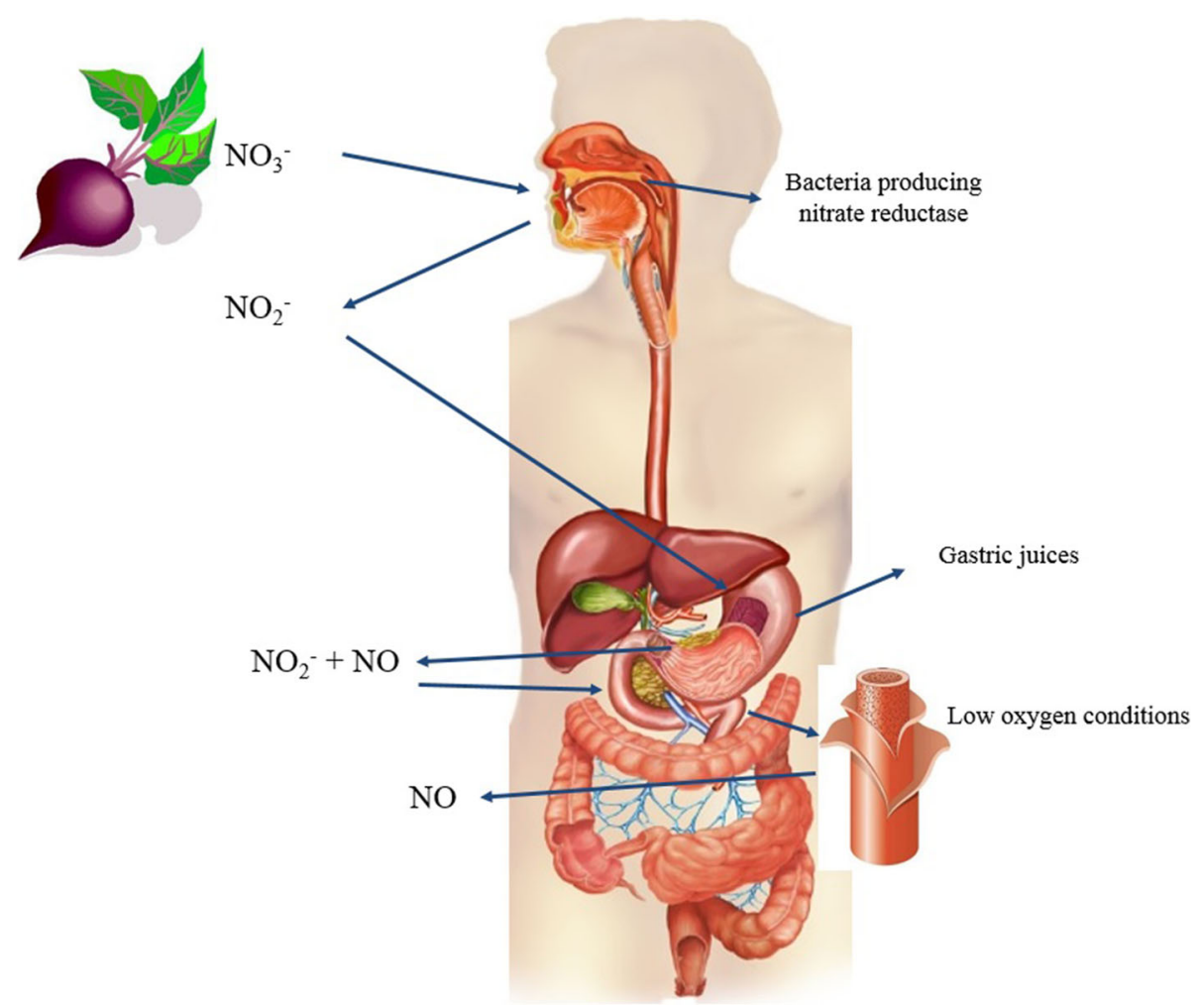

Fig. 1 Conversion of $\mathrm{NO}_{3}^{-}$in beetroot juice to $\mathrm{NO}$. The diagram shows how ingested $\mathrm{NO}_{3}^{-}$is transformed by bacteria in the mouth containing nitrite reductase to $\mathrm{NO}_{2}^{-}$. Once in the gut, $\mathrm{NO}_{2}^{-}$enters the bloodstream and, under conditions of hypoxia, is used to generate $\mathrm{NO}$ 
ventilatory threshold (VT) [27]; lowering $\mathrm{VO}_{2}$ by $-3 \%$ during a kayaking test conducted at $60 \% \mathrm{VO}_{2 \max }[38]$ and during a cycle ergometry test conducted by recreation sport athletes [45] and cyclists [34] at 45-70\% $\mathrm{VO}_{2 \max }$; increasing performance by $12-17 \%$ in cycle ergometry tests until exhaustion conducted at intensities of 60 to $90 \%$ $\mathrm{VO}_{2 \max }$ by recreation sport athletes [37, 42], and by $22 \%$ when conducted at a $70 \%$ intensity between VT and $\mathrm{VO}_{2 \max }$ [36]; and finally, improving times by $2.8 \%$ in trained cyclists conducting cycle ergometery tests of $4 \mathrm{~km}$ [33], $10 \mathrm{~km}(1.2 \%)$ [34], $16 \mathrm{~km}(2.7 \%)$ [33] and 50 miles $(0.8 \%)$ [35]. However, besides the effects of NO mentioned above, other impacts need to be considered. Accordingly, it has been described that the effect of increased blood flow induced by NO is specific to type II muscle fibres [20]. Moreover, in type II muscle fibres, beetroot juice intake has been found to improve the release and later reuptake of calcium from the sarcoplasmic reticulum [52]. This could translate to an increased capacity for muscle strength production of these type II muscle fibres. Such effects of NO could mean a physiological advantage for efforts involving the recruitment of type II muscle fibres, such as intermittent, high-intensity efforts. Hence, given the scarce yet growing number of studies that have addressed the effects of beetroot juice supplementation on this type of intermittent, high-intensity effort [38, 53-60], here we review the results of experimental studies that have specifically examined in adults (whether athletes or not) the effects of beetroot juice supplementation on intermittent, high-intensity efforts.

\section{Methodology}

We identified all studies that have assessed the effects of BJ supplementation on intermittent, high-intensity efforts by searching the databases Dialnet, Elsevier, Medline, Pubmed and Web of Science published up until March 31, 2017 using the keywords: beet OR beetroot OR nitrate OR nitrite (concept 1) AND supplement OR supplementation OR nutrition OR "sport nutrition" (concept 2) AND exercise OR sport OR "physical activity" OR effort OR athlete (concept 3).

Two of the present authors (E.C and P.G-F) first eliminated duplicate articles and then removed descriptions of studies that were not experimental, were not written in English or Spanish, or were published before 2010. This meant that all the studies reviewed were published over the period January 1, 2010 to March 31, 2017. Next, these two same authors applied a set of exclusion criteria to ensure the selection only of studies specifically designed to assess the effects of BJ supplementation on intermittent, high-intensity efforts:

- Studies performed in non-adults (samples including subjects aged $<18$ or $>65$ years).
- Studies conducted in vitro or in animals.

- Studies in which the direct effects of BJ were not determined.

- Studies in which impacts were examined on exercises that did not comply with the characteristics of intermittent, high-intensity efforts.

If there was disagreement about whether a given study met the inclusion/exclusion criteria, the opinion of a third researcher (F.M-O) was sought.

\section{Results \\ Study selection}

Of 738 studies identified in the search, 359 were left after eliminating repeated records. Once, the titles and abstract of these 359 publications were reviewed, 212 full text articles were indentified and retrieved for assessment, of which 9 articles met the elegibility criteria (Fig. 2).

\section{Study characteristics}

The nine studies selected for our review included a total of 120 subjects, 107 of whom were men and 13 women.

In five of these studies $[38,53,54,57,59]$, the effects of a single beetroot juice supplement (acute effects) were assessed. The supplement was taken $120 \mathrm{~min}$ before exercise in one study [53], $150 \mathrm{~min}$ before exercise in two [57, 59] and $180 \mathrm{~min}$ before exercise in the remaining two [38, 54].

In the remaining four studies, the effects of chronic beetroot juice supplementation were examined $[55,56,58,60]$. The supplementation periods were 5 days in one study [60], 6 days in two $[55,58]$ and 7 days in the fourth study [56].

Doses of $\mathrm{NO}_{3}^{-}$ingested ranged from $\sim 5 \mathrm{mmol}$ [38] to $\sim 11.4 \mathrm{mmol}$ [57]. In addition, one study examined the efficacy of beetroot juice taken separately or in combination with sodium phosphate [55].

In four of the nine studies reviewed, participants were competition athletes $[38,55,57,59]$ and in the other five they were recreation sport or low-level competition athletes $[53,54,56,58,60]$. Only one of the study populations included athletes of individual sports modalities [38], the rest of the studies were conducted in players of team sports [53-60].

The tests used to assess performance were a 30-s duration cycle ergometer test in one [59] and high-intensity, intermittent exercises in the remaining studies with work intervals ranging from $6 \mathrm{~s}$ [58] to $60 \mathrm{~s}$ [60] and rest periods from $14 \mathrm{~s}$ [56] to $4 \mathrm{~min}$ [60]. The types of tests employed were running at maximum speed in three studies [55-57], cycle ergometry in four [53, 54, 59, 60], one of which was an isokinetic test [59], a kayak ergometer test in one [38] and bench press strength training in the remaining study [58]. 


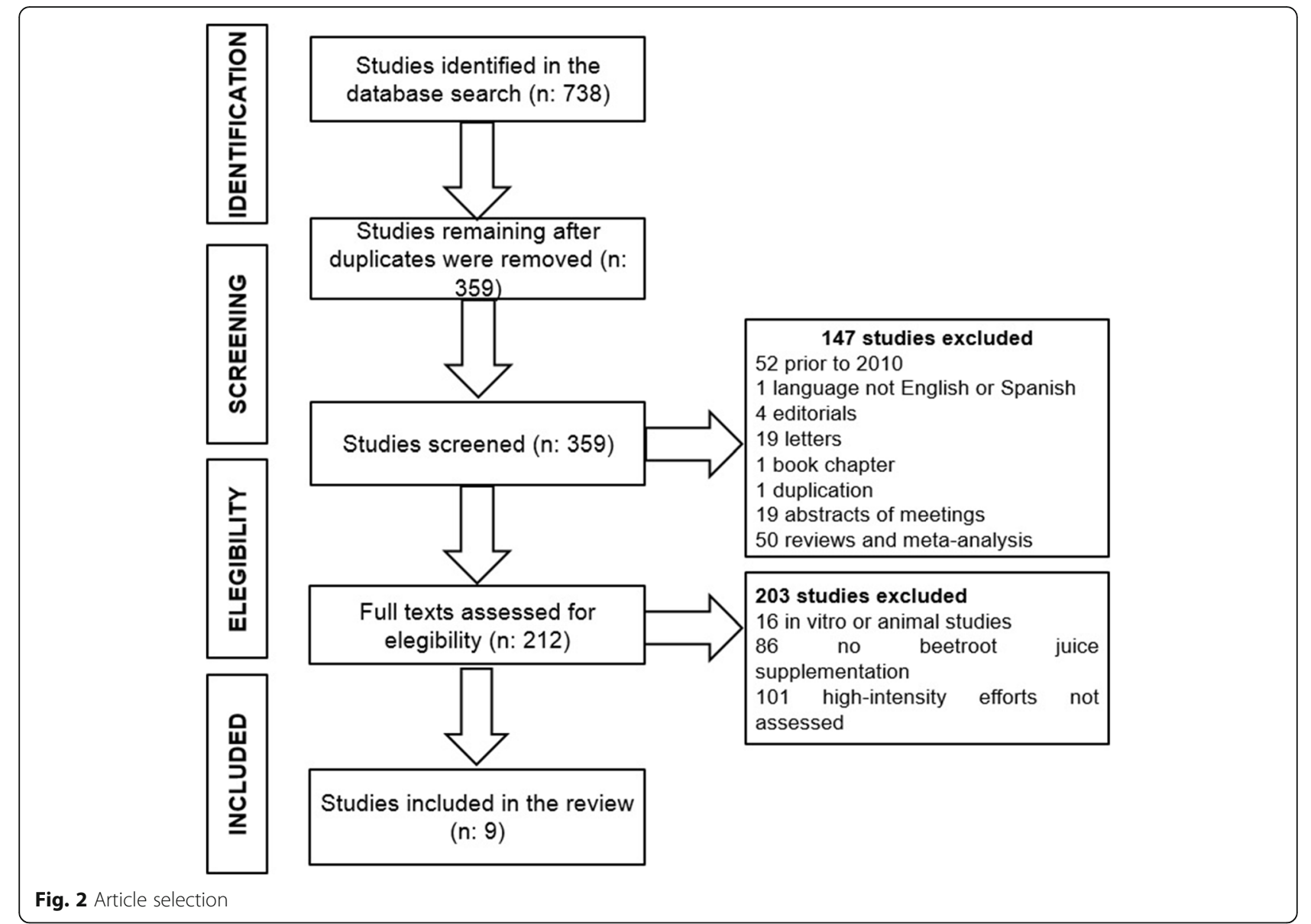

The beetroot juice intervention led to significantly improved performance in four of the studies [54, 56, 58, 60], while in another four no such effects were observed $[38,55,57,59]$. In the remaining study, an ergolytic, or reduced performance, effect was noted in relation to the placebo treatment.

\section{Study results}

In Table 1 we summarize the results of the nine studies reviewed and provide details on the participants, experimental conditions, supplement regimens, and performance tests employed.

\section{Discussion}

Effects of chronic supplementation with beetroot juice on intermittent, high-intensity exercise efforts

Four of the studies reviewed tested the effects of taking beetroot juice supplements for 5 to 7 days on intermittent, high-intensity efforts $[55,56,60]$ or on a resistance training session [58]. Three of these studies detected a significant effect of beetroot juice supplementation $[56,58,60]$ while in the remaining study, no significant difference compared with the placebo was noted [55].

\section{Effects of chronic supplementation with beetroot juice on resistance training}

Resistance training is used to improve muscular hypertrophy, strength, power and muscular endurance [61]. Training sessions targeting muscle hypertrophy include workloads of around $70-85 \% 1 \mathrm{RM}$ and 8-12 repetitions, while those aiming to improve muscular endurance include loads of around 50\% $1 \mathrm{RM}$ and some 15-25 repetitions [62]. Such exercise sessions are largely dependent on glycolytic metabolism; the lactate threshold in resistance training exercises such as half squat is detected at $\sim 25 \% 1$ RM [63, 64]. To determine the effects of 6 days of beetroot juice supplementation $\left(6.4 \mathrm{mmol} \mathrm{NO}_{3}\right)$ on resistance training sessions designed to improve local muscular hypertrophy and endurance, in the study by Mosher et al. reviewed here [58], the number of bench press repetitions accomplished in three sets using loads equivalent to $60 \% 1 \mathrm{RM}$ was recorded. Results indicated that supplementation increased the number of repetitions in the three exercise sets improving session performance by $18.9 \%$.

In an earlier investigation, the effects of sodium bicarbonate supplements were assessed in a similar study to the one by Mosher et al. [58]. Subjects performed 3 sets until exhaustion with loads of $10-12 \mathrm{RM}$ in three exercises 
Table 1 Summary of the results obtained in studies examining the impacts of beetroot juice supplements on intermittent high intensity exercise performance

\begin{tabular}{|c|c|c|c|c|c|}
\hline Reference & Subjects & Study design & Dose & Exercise test & Results \\
\hline Muggeridge et al. [38] & $\begin{array}{l}\text { Trained kayakers } \\
(\text { male, } n=8) \\
\left(\mathrm{VO}_{2 \text { peak }} 49.0\right. \\
\left. \pm 6.1 \mathrm{ml} \cdot \mathrm{kg} \cdot \mathrm{min}^{-1}\right)\end{array}$ & $\begin{array}{l}\text { Single-blind, } \\
\text { randomized, } \\
\text { cross-over }\end{array}$ & 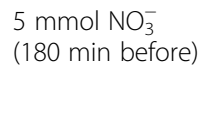 & $\begin{array}{l}\text { Kayak ergometer: } \\
5 \times 10 \text { s sprint-rest } \\
50 \mathrm{~s}\end{array}$ & $\begin{array}{l}+4 \% \text { average power } \\
(420 \pm 23 \text { vs } 404 \pm 24 \mathrm{~W})\end{array}$ \\
\hline $\begin{array}{l}\text { Martin } \\
\text { et al. [53] }\end{array}$ & $\begin{array}{l}\text { Recreation team } \\
\text { sport players (male, } \\
n=16)\left(\mathrm{VO}_{2 \text { peak }}\right. \\
\left.47.2 \pm 8.5 \mathrm{ml} \cdot \mathrm{kg} \cdot \mathrm{min}^{-1}\right)\end{array}$ & $\begin{array}{l}\text { Double-blind, } \\
\text { randomized, } \\
\text { cross-over }\end{array}$ & $\begin{array}{l}6.4 \mathrm{mmol} \mathrm{NO}- \\
\text { (120 min before) }\end{array}$ & $\begin{array}{l}\text { Cycle ergometer: } \\
\text { sets until exhaustion } \\
\text { of } 8 \mathrm{~s}-\text { rest } 30 \mathrm{~s}\end{array}$ & $\begin{array}{l}-13 \% \text { reps }(13 \pm 5 \text { vs } 15 \pm 6) \\
\text { and }-17 \% \text { total work }(49.2 \pm \\
24.2 \text { vs } 57.8 \pm 34.0 \mathrm{~kJ})\end{array}$ \\
\hline Aucouturier et al. [54] & $\begin{array}{l}\text { Recreation team sport } \\
\text { players (male, } n=12 \text { ) } \\
\left(\mathrm{VO}_{2 \text { peak }} 46.6 \pm 3.4\right. \\
\mathrm{ml} \cdot \mathrm{kg} \cdot \mathrm{min}^{-1} \text { ) }\end{array}$ & $\begin{array}{l}\text { Single-blind, } \\
\text { randomized, } \\
\text { cross-over }\end{array}$ & $\begin{array}{l}10.9 \mathrm{mmol} \mathrm{NO} \\
\text { (180 min before) }\end{array}$ & $\begin{array}{l}\text { Cycle ergometer: } \\
\text { sets until exhaustion } \\
\text { of } 15 \mathrm{~s} \text { at } 170 \% \\
\text { MAP-rest } 30 \mathrm{~s}\end{array}$ & $\begin{array}{l}+20 \% \text { reps }^{*}(26.1 \pm 10.7 \mathrm{vs} \\
21.8 \pm 8.0) \text { and } 18 \% \text { total } \\
\text { workload }^{*}(168.2 \pm 60.2 \text { vs } \\
142.0 \pm 46.8 \mathrm{~kJ})\end{array}$ \\
\hline $\begin{array}{l}\text { Buck } \\
\text { et al. [55] }\end{array}$ & $\begin{array}{l}\text { Amateur team sport } \\
\text { players (female, } n=13) \\
\left(\mathrm{VO}_{2 \text { peak }} \text { not specified) }\right.\end{array}$ & $\begin{array}{l}\text { Double-blind, } \\
\text { randomized, } \\
\text { Latin-square }\end{array}$ & $\begin{array}{l}\mathrm{BJ}: 6.4 \mathrm{mmol} \mathrm{NO}-- \\
(6 \text { days) } \mathrm{BJ}+\mathrm{SP}: \\
6.4 \mathrm{mmol} \mathrm{NO} \mathrm{NO}_{3}^{-}+ \\
50 \mathrm{mg} \cdot \mathrm{kg} \text { lean } \\
\text { mass SP (6 days) }\end{array}$ & $\begin{array}{l}\text { PRE, MID and POST } \\
\text { simulation team } \\
\text { sport matches: } 6 \times(20 \\
\text { m sprint + rest } 25 \mathrm{~s})\end{array}$ & $\begin{array}{l}\text { BJ: }-0.2 \% \text { total sprint time } \\
\text { per set }(69.8 \pm 4.9 \text { vs } 69.97 \\
\pm 4.2) \text { BJ }+ \text { SP: }-2 \% \text { total } \\
\text { sprint time per set }(68.9 \pm \\
5.1 \text { vs } 69.97 \pm 4.2)\end{array}$ \\
\hline Thompson et al. [56] & $\begin{array}{l}\text { Recreation team sport } \\
\text { players (male, } n=16) \\
\left(\mathrm{VO}_{2 \text { peak }} 50 \pm 7\right. \\
\left.\mathrm{ml} \cdot \mathrm{kg} \cdot \mathrm{min}^{-1}\right)\end{array}$ & $\begin{array}{l}\text { Double-blind, } \\
\text { randomized, } \\
\text { cross-over }\end{array}$ & $\begin{array}{l}12.8 \mathrm{mmol} \\
\mathrm{NO}_{3}^{-} \text {(7 days) }\end{array}$ & $\begin{array}{l}\text { MID and POST simulated } \\
\text { team-sport matches: } \\
2 \times[5 \times(6 \mathrm{~s} \text { cycle ergometry } \\
\text { sprint }+ \text { rest } 14 \mathrm{~s})]\end{array}$ & $\begin{array}{l}5 \% \text { work volume at MID* } \\
(63 \pm 20 \text { vs } 60 \pm 18 \mathrm{~kJ}), \\
2 \% \text { POST }(60 \pm 17 \text { vs } 59 \\
\pm 16 \mathrm{~kJ}) \text { and } 4 \% \text { whole } \\
\text { session }(123 \pm 19 \text { vs } \\
119 \pm 17 \mathrm{~kJ})\end{array}$ \\
\hline $\begin{array}{l}\text { Clifford } \\
\text { et al. [57] }\end{array}$ & $\begin{array}{l}\text { Competition team } \\
\text { sport players (male, } \\
n=20)\left(\mathrm{VO}_{2 \text { peak }}\right. \\
\text { not specified) }\end{array}$ & $\begin{array}{l}\text { Double-blind, } \\
\text { independent } \\
\text { groups design }\end{array}$ & $\begin{array}{l}11.4 \mathrm{mmol} \mathrm{NO}_{3}^{-} \\
\text {(150 min before) }\end{array}$ & $\begin{array}{l}\text { 2XRST: } 20 \times(30 \mathrm{~m} \\
\text { sprint-rest } 30 \mathrm{~s})\end{array}$ & $\begin{array}{l}-1 \% \text { average sprint time } \\
\text { RST1 ( } 4.65 \pm 0.3 \text { vs } 4.7 \pm \\
0.2 \mathrm{~s}) \text { and }-2 \% \text { RST2 } \\
(4.66 \pm 0.2 \text { vs } 4.77 \pm 0.2 \mathrm{~s}) \\
\text { and }-2 \% \text { fastest sprint RST1 } \\
(4.41 \pm 0.2 \text { vs } 4.48 \pm 0.1 \mathrm{~s}) \\
\text { and }-3 \% \text { RST2 }(4.38 \pm 0.2 \\
\text { vs } 4.53 \pm 0.2 \mathrm{~s})\end{array}$ \\
\hline $\begin{array}{l}\text { Mosher } \\
\text { et al. [58] }\end{array}$ & $\begin{array}{l}\text { Recreation sport } \\
\text { players (male, } \\
n=12)\left(\mathrm{VO}_{2 \text { peak }}\right. \\
\text { not specified) }\end{array}$ & $\begin{array}{l}\text { Double-blind, } \\
\text { randomized, } \\
\text { cross-over }\end{array}$ & $\begin{array}{l}6.4 \mathrm{mmol} \\
\mathrm{NO}_{3}^{-} \text {(6 days) }\end{array}$ & $\begin{array}{l}\text { Bench press: } 3 \times \\
\text { (maximum number } \\
\text { reps at } 60 \% 1 \text { RM) }\end{array}$ & $\begin{array}{l}+19 \% \text { weight lifted in } \\
\text { session and improved } \\
\text { no. of reps } \mathrm{S1}^{*} \cdot \mathrm{S2}^{*} \cdot \mathrm{S}^{*} \\
\text { and whole session. } \\
\text { improvements not } \\
\text { specified }\end{array}$ \\
\hline $\begin{array}{l}\text { Rimer } \\
\text { et al. [59] }\end{array}$ & $\begin{array}{l}\text { Competition sport } \\
\text { players (male, } n=13) \\
\left(\mathrm{VO}_{2 \text { peak }} \text { not specified) }\right.\end{array}$ & $\begin{array}{l}\text { Double-blind, } \\
\text { randomized, } \\
\text { cross-over }\end{array}$ & $\begin{array}{l}11.2 \mathrm{mmol} \mathrm{NO}_{3}^{-} \\
\text {(150 min before) }\end{array}$ & $\begin{array}{l}\text { Isokinetic cycle } \\
\text { ergometer: Wingate } \\
\text { 30-s test }\end{array}$ & $\begin{array}{l}-1 \% \text { peak power }(1173 \\
\pm 255 \text { vs } 1185 \pm 249 \mathrm{~W}) \\
\text { and }-1 \% \text { total work } \\
(22.8 \pm 4.8 \text { vs } 23 \pm 4.8 \mathrm{~W})\end{array}$ \\
\hline Wylie et al. [60] & $\begin{array}{l}\text { Recreation team sport } \\
\text { players }(\text { male, } n=10) \\
\left(\mathrm{VO}_{2 \text { peak }} 58 \pm 8\right. \\
\left.\mathrm{ml} \cdot \mathrm{kg} \cdot \mathrm{min}^{-1}\right)\end{array}$ & $\begin{array}{l}\text { Double-blind, } \\
\text { randomized, } \\
\text { cross-over design }\end{array}$ & $\begin{array}{l}8.4 \mathrm{mmol} \\
\mathrm{NO}_{3}^{-} \text {(5 days) }\end{array}$ & $\begin{array}{l}\text { Cycle ergometer: } 24 \text { x } \\
\text { (6 s sprint-rest } 24 \text { s) } \\
\text { Cycle ergometer: } 7 x \\
\text { (30 s sprint-rest } 4 \text { min) } \\
\text { Cycle ergometer: } 6 x \\
\text { (60 s sprint-rest } 60 \text { s) }\end{array}$ & $\begin{array}{l}+5 \% \text { mean average power } \\
(568 \pm 136 \text { vs } 539 \pm 136 \mathrm{~W}) \\
\text { and }+1 \% \text { mean peak power } \\
(792 \pm 159 \text { vs } 782 \pm 154 \mathrm{~W}) \\
\text { in } 24 \times(6 \text { s sprint-rest } 24 \text { s); } \\
-1 \% \text { mean average power } \\
(558 \pm 95 \text { vs } 562 \pm 94 \mathrm{~W}) \text { and } \\
-1 \% \text { mean peak power }(768 \\
\pm 157 \text { vs } 776 \pm 142 \mathrm{~W}) \text { in } 7 \times \\
(30 \text { s sprint-rest } 4 \text { min) }\end{array}$ \\
\hline
\end{tabular}

BJ Beetroot juice, MID Half-time simulation match, $n$ Sample size; no Number, $N_{3}^{-}$nitrate concentration in the drink, MAP Maximum aerobic power, $P O S T$ End simulation match, $P R E$ Before simulation match, Rep Repetition, $R S T$ Repeated sprint test, $S P$ Sodium phosphate, $V O_{2 p e a k}$ Peak oxygen consumption, ${ }^{*}$ statistically significant differences

targeting the lower limbs [65]. Results indicated that, like the beetroot juice, sodium bicarbonate supplementation led to more repetitions in the session [65]. However, in parallel with the increasing number of repetitions, blood lactate concentrations also rose $(\sim 2.5 \mathrm{mmol})$ [65]. This was not observed in Mosher's study [58].
If we consider the nature of resistance training, the athlete passes from a resting condition to a situation demanding high energy levels during the first repetitions of a set. Because the phosphagen system is the main energy pathway in rest-exercise transitions [66], phosphocreatine reserves may be depleted in response to a resistance training 
exercise set. Recovering these reserves takes some 3$5 \mathrm{~min}$ [67]. Given that phosphocreatine resynthesis is dependent on oxidative metabolism [68] and that beetroot juice has an ergogenic effect on exercise modalities with a major oxidative metabolism component [50], it could be that this supplement accelerated this recovery during the rest period in Mosher's study ( $2 \mathrm{~min}$ ) and thus avoided progressive phosphocreatine depletion throughout the session. In turn, this faster rate of resynthesis would attenuate the increasing levels of adenosine diphosphate (ADP) and inorganic phosphates [68]. Both these metabolites have been associated with the appearance of muscular fatigue [69]. Hence, by delaying the build-up of critical levels of these metabolites, the appearance of fatigue will be delayed and this will allow for more repetitions in sets until exhaustion [58]. $\mathrm{NO}_{3}^{-}$supplementation could also improve muscle efficiency and contractile capacity by promoting the release of calcium from the sarcoplasmic reticulum in the muscle cells and its reuptake $[52,69]$. Thus, a train of action potentials leading to an increased supply of calcium to the muscle fibre will increase the strength of muscle contraction [13].

\section{Effects of chronic supplementation with beetroot juice on intermittent high-intensity exercise efforts}

Some sport modalities such as team, racket or combat sports require bursts of high-intensity efforts followed by rest periods. Thus, in team sports, high-intensity efforts $(\sim 3-4 s)$ are interspersed with variable active rest periods [70]. In racket sports like tennis, efforts last 7$10 \mathrm{~s}$ and rest periods $10-16 \mathrm{~s}$ (between points) and/or 60-90 s (side changes) [71]. Finally, in combat sports more intense efforts are 15-30 s long and active rest periods are 5-10 s long every $5 \mathrm{~min}$ [72]. In all these sports modalities, the capacity to repeat high-intensity efforts with only short recovery periods is considered a performance indicator [73]. This means that higher level athletes are able to maintain performance in successive high-intensity intervals over a long time period [74].

To find out if beetroot juice supplementation would improve this ability to repeat high-intensity efforts during a team sport match, Thompson et al. [56] administered beetroot juice over 7 days to a group of athletes $\left(12.8 \mathrm{mmol} \mathrm{NO}_{3}^{-}\right)$. The performance test consisted of two blocks of five 6-s sets of sprints on a cycle ergometer with 14-s active recovery periods in the middle and end of a simulated match lasting $2 \times 40 \mathrm{~min}$ [56]. The results of this study indicated a total work volume improved by $3.5 \%$ in the whole session, though this improvement was greater at the end of the first half (at half time).

If we again consider the nature of this type of exercise, it has been established that it involves the recruitment of type II muscle fibres $[75,76]$, which are more powerful though show more fatigue than type I units [77]. This lesser resistance to fatigue has been related to reduced blood flow and myoglobin concentrations in these muscle fibres compared to type I. Hence, type II muscle fibres are designed to promote non oxidative pathways and have shown a greater creatine storage capacity [78] for an enhanced metabolism of phosphocreatine [79] and proteins with a buffering effect at the intracellular level such as carnosine [80], favouring a glycolytic type metabolism.

Animal studies have shown that increased blood flow in response to $\mathrm{NO}_{3}^{-}$supplementation is greater in type II compared to type I muscle fibres [20]. This greater irrigation and oxygen availability in the recovery period along with a greater creatine storage capacity of motor type II units [78] (promoting phosphocreatine resynthesis [79]) means that during an exercise effort followed by a short rest period $\left(\begin{array}{ll}14 & \text { s}\end{array}\right)$, beetroot juice supplementation could delay phosphocreatine depletion during successive sprints and explain the improvements noted by Thompson et al. [56].

Despite such greater effects of $\mathrm{NO}_{3}^{-}$supplementation on type II versus type I muscle fibres, animal studies have also shown that effects on calcium release and reuptake in the muscle cell sarcoplasmic reticulum is greater in type II than type I muscle fibres [52]. Accordingly, because of the important role of type II muscle fibres during sprints $[75,76]$, supplementation could have led to an improved capacity to generate muscle power and thus explain the significant improvements in performance observed by Thompson's group.

Buck et al. [55] examined the effects of 6 days of supplementation with beetroot juice $\left(6.4 \mathrm{mmol} \mathrm{NO}_{3}^{-}\right)$or sodium phosphate (50 mg.kg lean mass) on performance in a test consisting of repeated sprints as 6 sets of $20 \mathrm{~m}$ and 25-s of rest between sets in the middle and end of a simulated match lasting $60 \mathrm{~min}$. The beetroot juice intervention did not improve performance at these sprints, yet did do so when taken along with sodium phosphate (2\%) compared with placebo, though this improvement was of lesser magnitude than when the subjects only took sodium phosphate supplements (5\%). These findings suggest that, unlike beetroot juice, sodium phosphate intake may have an ergogenic effect in this protocol. If we compare the tests used by Buck et al. [55] and Thompson et al. [56], work periods were shorter ( $2-3$ vs 6 s), while rest periods were longer ( 25 vs $14 \mathrm{~s})$. Therefore it could be that $2-3 \mathrm{~s}$ efforts lead to a significantly lower reduction of phosphocreatine reserves at the end of these efforts. Further, the $25 \mathrm{~s}$ of rest approaching the $30 \mathrm{~s}$ in which the recovery of $50 \%$ of phosphocreatine stores takes place [67], may have been sufficient to stabilize reserves of phosphocreatine and therefore avoid the appearance of fatigue [81].

Another study investigated the effects of longer term supplementation (5 days) with beetroot juice $(8.4 \mathrm{mmol}$ $\mathrm{NO}_{3}^{-}$), this time on performance in a repeated high- 
intensity test [60]. These authors sought to determine supplementation effects on different exercise protocols. Subjects performed a session consisting of twenty four 6-s sets of work and $24 \mathrm{~s}$ of rest between sets, a second session of two 30-s sets of work and 2 min of rest between sets and a third session of six 6-s sets and $60 \mathrm{~s}$ of rest between sets. As did Thompson et al. [56], Wylie et al. [60] selected 6-s exercise sets in the first session though rest intervals were longer ( 24 vs $14 \mathrm{~s}$ ). Another difference was that the participants had not first undergone fatigue (in the simulated team sport match) before the performance test. Notwithstanding, results were similar in that mean power generated in the sets over a whole session improved by $\sim 7 \%$. However, improvements across the $24 \times 6-24$ protocol were not comparable to those recorded in the other two tests, in which no significant improvements were recorded.

In the test protocols including 30-s and 60-s work efforts, beetroot juice supplementation resulted in no improvements in any indicators of performance [60]. These protocols consisting of longer duration work intervals mainly involve a glycolytic type metabolism and in smaller measure elicit the high-energy phosphagen system. An increase in glycolysis leads to increased $\mathrm{H}^{+}$production, lowering $\mathrm{pH}$ [82]. To avoid increasing acidosis, a series of responses targeted at reducing phosphofructokinase take place including diminished glycolysis [83] and phosphocreatine resynthesis [84], and muscle contractibility modifications [85]. Such responses manifest as reduced non aerobic metabolism or a reduced capacity for muscle power and strength, in other words, fatigue [86]. Supplements such as $\beta$-alanine (which increases muscle carnosine concentrations [87], a protein that acts as a buffer inside the cell [88]) and sodium bicarbonate [89] (main extracellular buffering agent) have shown ergogenic effects on performance at high-intensity efforts involving the predominance of glycolytic metabolism [90]. The combined effect of these supplements is greater than the impact of each supplement on its own [91].

Although beetroot juice supplementation induces vasodilation and increased blood flow (in type II muscle fibres, recruited mainly in exercise bouts of 30 to $60 \mathrm{~s}$ duration), increasing available oxygen in the muscles, rather than being activated because of a lack of oxygen (anaerobiosis), non-oxygen dependent pathways are activated because of a greater demand for energy production via oxidative phosphorylation. Thus, these effects, although they potentiate oxidative phosphorylation, have no repercussions on glycolytic energy metabolism. Hence, as beetroot juice has no alkalizing effect supplementation with this product is unable to reduce acidosis, as the main factor limiting performance at efforts lasting 30-60 s. However, potentiating effects on aerobic metabolism increases the speed of phosphocreatine resynthesis, dependent on oxidative phosphorylation. This means it may be effective for repeated high-intensity efforts whose duration is close to 6-10 $\mathrm{s}$, in which high energy phosphagens contribute mainly to the metabolism [92] and the work volume is sufficient to cause significant depletion, which when faced with short rest intervals leads to progressive depletion and consequently to fatigue. Accordingly, beetroot juice supplements can have an ergogenic effect when exercise efforts are intermittent, maximum intensity, short-duration (6-10 s) and interspersed with brief recovery periods $(<30 \mathrm{~s})$.

\section{Effects of acute beetroot juice supplementation on intermittent high-intensity efforts}

Five of the studies reviewed here were designed to analyze the effects of a single beetroot juice supplement on intermittent high-intensity exercise efforts [38, 53, 54, 57, 59]. Aucouturier et al. [54] administered the supplement $\left(\sim 10.9 \mathrm{mmol} \mathrm{NO}_{3}^{-}\right)$to a group of recreation athletes 180 min before performing sets until exhaustion consisting of $15 \mathrm{~s}$ of pedalling at $170 \% \mathrm{VO}_{2 \max }$ followed by $30-\mathrm{s}$ rest periods. The authors reported that the beetroot supplement gave rise to improvements close to $20 \%$ in the number of repetitions performed and the total work completed in the session [54]. Besides the number of sets completed and the work accomplished, these authors measured red blood cell concentrations at the microvascular level. The beetroot juice, apart from improving performance, was found to increase microvascularization. Such improvements are considered a beneficial effect on oxygen exchange in the muscle [93]. Accordingly, these oxygen availability improvements produced at the muscular level could have potentiated oxidative phosphorylation during rest periods, and, given their brief duration, could have increased phosphocreatine resynthesis when subjects took the supplement rather than the placebo. Thus, supplementation would have delayed the depletion of phosphocreatine reserves and this effect was likely the cause of the improvements observed in the repeated sets of intermittent sprints [94, 95].

As did Aucouturier et al. [54], Muggeridge et al. [38] examined the effect of beetroot juice $\left(5 \mathrm{mmol} \mathrm{NO}_{3}^{-}\right)$taken $180 \mathrm{~min}$ before an intermittent effort consisting of 5 sets of $10 \mathrm{~s}$ in a kayak ergometer with 50 -s interset rest periods. In this study, though supplementation seemed to have a greater effect on the power generated in the last two sets, the improvement noted lacked significance. However, if we compare this study with the study by Aucouturier et al. [54], work periods in the Muggeridge study [38] were shorter (10 vs $15 \mathrm{~s}$ ) and rest periods were much longer (50 vs $30 \mathrm{~s}$ ). Ten second maximum intensity intervals have a significantly reduced capacity compared with $15 \mathrm{~s}$ intervals to deplete phosphocreatine reserves. Moreover, the rate of phosphocreatine replacement has a first phase in which up to $50 \%$ of these reserves can be replenished in $30 \mathrm{~s}$ and 
$100 \%$ in $3-5$ min [67]. Also if we consider that the main effect of beetroot juice supplements is linked to an improved rate of phosphocreatine resynthesis, it is possible that as there is less depletion and a rest period in which there is almost complete recovery of phosphocreatine reserves, supplementation could not have exerted any beneficial effect in the study by Muggeridge et al. [38]. However, despite the short work periods and relatively long recovery periods and the fact that the power developed in the last sets showed an improved trend following supplementation, it is possible that lengthening intervals in a set until exhaustion would have been beneficial and given rise to similar results to those observed by Aucouturier et al. [54].

Rimer et al. [59] assessed the effects of acute supplementation (150 min before exercise) with beetroot juice (11.2 $\mathrm{mmol} \mathrm{NO}_{3}^{-}$) on performance in a maximal intensity 3-s test on an isoinertial cycle ergometer and a 30-s test on an isokinetic cycle ergometer. Supplementation was effective at improving pedalling cadence, and thus the power generated, in the 3-s test. However, no such effect was observed in the isokinetic test.

The improvements noted by Rimer's group in the 3-s test affected pedalling cadence. Because of the link between such improvements and an increase in muscle shortening velocity [96] and the proposal that NO could increase this velocity $[97,98]$, the authors suggested that beetroot juice could have a beneficial effect on power output [59]. This rationale was also used to explain the lack of changes produced in the 30-s test in which pedalling cadence was fixed at $120 \mathrm{rpm}$. This means that any improved power production in the isokinetic test could only occur if there was an increase in power at a constant shortening velocity [59], since power equals force times velocity.

In a later investigation performed in CrossFit athletes, it was reported that supplementation with $\mathrm{NO}_{3}^{-}$salts $(8 \mathrm{mmol}$ $\mathrm{NO}_{3}$ ) rather than beetroot juice was able to improve performance in a 30-s cycle ergometry test [99]. However, unlike the 30-s test used by Rimer et al. [59], the test was isoinertial. The difference between the 2 cycle ergometers is that while in the isokinetic test pedalling cadence is prefixed and improvements only in strength are possible, in an isoinertial test the workload is fixed and any power improvements produced manifest as improvements in pedalling cadence. Given that beetroot juice supplementation could improve power development as a consequence of a reduced muscle shortening velocity $[59,97,98]$, the isokinetic cycle ergometer is perhaps not sufficiently sensitive to assess the effects of this supplementation. Considering the beneficial effects on cadence and power output observed in the cycle ergometry 3-s [59] and 30-s [99] tests, it seems that beetroot juice supplementation could have a beneficial effect on this type of effort.
In a fourth study, Clifford et al. [57] assessed the effects of a single intake of beetroot juice on performance in a test of 20 sets of $30 \mathrm{~m}$ sprints interspersed with 30 -s rest periods. These authors observed no ergogenic effects of the supplementation. However, if we look at the characteristics of the test employed by the researchers, we find that the work periods (close to $3 \mathrm{~s}$ ) together with the $30 \mathrm{~s}$ recovery periods could be sufficient for the subjects to have recovered their phosphocreatine levels in the rest intervals, minimizing the possible ergogenic effects of the supplementation.

A novel indicator used in this study by Clifford et al. [57] was the counter-movement jump (CMJ) test performed before the intermittent velocity test and in the rest periods. Performance in this test is determined by the contractile properties of muscle and by neuromuscular control of the entire musculoskeletal system [100]. Given that fatigue reflects the incapacity of the neuromuscular system to maintain the level of power required [101], losses in CMJ height at the end of exercise are taken as an indicator of muscular fatigue [102].

In the study by Clifford's group [57], it was observed that the protocol of intermittent sprints gave rise to muscular fatigue. This fatigue can be the outcome of deficiencies in the muscle's contractile mechanism [101, 103]. Alternatively, strong eccentric actions of the hamstring muscles during sprints may produce muscle damage [104] and therefore modify the structure of the muscle fibre's sarcomeres. Thus, any loss in CMJ height could indicate muscle damage. While $\mathrm{CMJ}$ was monitored after the protocol of 20 sets of $30 \mathrm{~m}$ with 30 -s rest periods, a greater recovery of CMJ height was observed in the supplementation group. This suggests that beetroot juice could help preserve muscle structure during high-intensity efforts. Another explanation could be related to the vasodilation effect of beetroot juice [50] possibly helping muscle regeneration during early recovery. In future work, biomarkers of muscle damage or inflammation need to be examined.

In the fifth study, Martin et al. investigated the effects of beetroot juice $\left(6.4 \mathrm{mmol} \mathrm{NO}_{3}^{-}\right)$on repetitive sets until exhaustion each consisting of $8 \mathrm{~s}$ of work followed by $30 \mathrm{~s}$ of rest on a cycle ergometer [53]. No effects were detected on power output in the different sets. Moreover, a lower number of sets was accomplished in the session for the supplementation group versus placebo group. In effect, this was the only study to describe an ergolytic effect of beetroot juice. The authors argued that because of the scarce contribution of oxidative phosphorylation to energy metabolism during high-intensity efforts and that the ergogenic potential of this supplement is related to potentiating oxidative pathways, no beneficial effects are produced on this type of physical action. 
The results of the investigation by Martin et al. [53] conflict with those of others who did observe beneficial effects on performance in similar tests [54, 56, 58, 60]. Beetroot juice was taken 120 min before exercise. This regimen is not appropriate, as peak $\mathrm{NO}_{2}^{-}$ levels are produced $2-3 \mathrm{~h}$ after ingestion and it is recommended that supplementation should be taken at least $150 \mathrm{~min}-180 \mathrm{~min}$ before the high-intensity effort [32, 50]. Effectively, Aucouturier et al. [54] used a test of similar characteristics but the beetroot supplement was taken $180 \mathrm{~min}$ before the exercises, as recommended.

\section{Conclusions}

To date, few studies have examined the effects of supplementation with beetroot juice on short-duration high-intensity exercise efforts [38, 53-60] and observations so far will need confirmation in future studies:

- Supplementation with beetroot juice has been shown to diminish the muscular fatigue associated with high-intensity exercise efforts, though it is not known if this is achieved by reducing fatigue and muscle damage and/or promoting muscle regeneration postexercise.

- When faced with exercise efforts that could considerably deplete phosphocreatine reserves (sets of resistance training or repetitive sprints of around $15 \mathrm{~s}$ interspersed with short rest periods) and given that phosphocreatine resynthesis requires an oxidative metabolism, beetroot juice could help the recovery of phosphocreatine reserves and thus avoid its depletion during repeated efforts. In parallel, supplementation would limit the build-up of metabolites such as ADP and inorganic phosphates, which are known to induce muscular fatigue.

- Beetroot juice has been shown to improve the release and reuptake of calcium at the sarcoplasmic reticulum. This could help the power production associated with improvements in muscle shortening velocity. Nonisokinetic ergometers (in which movement velocity is not assessed) are sensitive to such improvements in power generation.

\section{Study limitations}

The main limitation of our review is the scarcity of studies that have examined the effects of beetroot juice supplementation on intermittent, high- intensity exercise. This limitation is also magnified by the varied design of the few studies available including different supplementation doses and regimens.

\section{Future lines of research}

- As it has been proposed that beetroot juice supplementation improves phosphocreatine resynthesis during the brief rest periods included in protocols of intermittent high-intensity exercise, future studies are needed to confirm via a muscle biopsy phosphocreatine levels during repeated high-intensity efforts.

- To examine the possible beneficial effect of beetroot juice on muscle shortening velocity reflected as improved pedalling cadence, future studies need to assess the ergogenic effect of this supplement in a single, constant-load test on an inertial cycle ergometer.

- To elucidate the mechanism whereby beetroot juice diminishes muscular fatigue and improves recovery from this fatigue, the effects of ingesting $\mathrm{NO}_{3}^{-}$on biomarkers of inflammation and muscle damage need to be addressed.

- According to the results of the study in which an ergolytic effect was produced in response to a single dose of beetroot juice administered 120 min before exercise, future investigations should determine the most appropriate timing of supplementation to optimize its ergogenic potential.

- Finally, owing to the possible beneficial impacts of beetroot juice, we will need to assess the interactions of beetroot juice with other supplements of proven ergogenic effects in this type of exercise effort such as caffeine, creatine, $\beta$-alanine and sodium bicarbonate.

\section{Acknowledgements}

Not applicable.

Funding

There were no sources of funding for this research.

Availability of data and materials

Data sharing not applicable to this article as no datasets were generated or analysed during the current study.

Authors' contributions

R.D. and M.V.G.-G. conceived and designed the review; E.C., P.G.-F. and F.M.O. selected the articles included; E.C., M.C.L.-E. and P.V.-H. analyzed the articles included; P.G.-F., F.M.-O. and P.V.-H. translated the manuscript into English; R.D., J.L.M.-M., E.C., S.F.S. and M.V.G.-C. prepared the figures and tables and drafted the manuscript; R.D., J.L.M.-M., E.C., P.G.-F., F.M.-O., M.C.L.-E., P.V.-H., S.F.S. and M.V.G.-C. edited and revised manuscript; R.D., J.L.M.-M., E.C., P.G.-F., F.M.-O., M.C.L.-E., P.V.-H., S.F.S. and M.V.G.-C. Approved the final version of the manuscript.

Ethics approval and consent to participate

Not applicable.

Consent for publication

Not applicable.

Competing interests

The authors declare that they have no competing interests. 


\section{Publisher's Note}

Springer Nature remains neutral with regard to jurisdictional claims in published maps and institutional affiliations.

\section{Author details}

${ }^{1}$ Physical Activity and Sport Sciences, College of Health Sciences, Alfonso X El Sabio University, Madrid, Spain. ${ }^{2}$ TecnoCampus. GRI-AFIRS, School of Health Sciences, Pompeu Fabra University, Mataró, Barcelona, Spain. ${ }^{3}$ NutriScience, C/Paco León, 1, 14010 Córdoba, Spain. ${ }^{4}$ Physical Activity and Sport Sciences, Physical Education Departament, University of Lavras, Lavras, Brazil.

\section{Received: 6 June 2017 Accepted: 7 December 2017}

\section{Published online: 05 January 2018}

\section{References}

1. Paton CD, Hopkins WG. Variation in performance of elite cyclists from race to race. Eur J Sport Sci. 2006;6:25-31.

2. Koncic MZ, Tomczyk M. New insights into dietary supplements used in sport: active substances, pharmacological and side effects. Curr Drug Targets. 2013;14:1079-92.

3. Australian Institute of Sport. ABCD classification system. 2017. Available online: http:// mww.ausport.gov.au/ais/nutrition/supplements/classification (Accessed on 11 Apr 2017).

4. Burke LM. Practical issues in evidence-based use of performance supplements: supplement interactions, repeated use and individual responses. Sports Med. 2017:47:79-100.

5. Close GL, Hamilton L, Philps A, Burke L, Morton JP. New strategies in sport nutrition to increase exercise performance. Free Radic Biol Med. 2016;5:30-7.

6. Burnley B, Jones AM. Oxygen uptake kinetics as a determinant of sports performance. Eur J Sport Sci. 2007;7:63-79.

7. Morton $\mathrm{RH}$. The critical power and related whole-body bioenergetic models. Europ J Appl Physiol. 2006;96:339-54.

8. Chamari K, Padulo J. 'Aerobic' and 'anaerobic' terms used in exercise physiology: a critical terminology reflection. Sports Med Open. 2015;1:9.

9. Gaitanos GC, Williams C, Boobis LH, Brooks S. Human muscle metabolism during intermittent maximal exercise. J Appl Physiol. 1993;75:712-9.

10. Chamari K, Ahmaidi S, Blum JY, Hue O, Temfemo A, Hertogh C, et al. Venous blood lactate increase after vertical jumping in volleyball athletes. Eur J Appl Physiol. 2001;85:191-4

11. Spencer MR, Gastin PB. Energy system contribution during 200- to 1500-m running in highly trained athletes. Med Sci Sports Exerc. 2001;33:157-62.

12. Jones AM. Influence of dietary nitrate on the physiological determinants of exercise performance: a critical review. Appl Physiol Nutr Metab. 2014;39:1019-28.

13. Stamler JS, Meissner G. Physiology of nitric oxide in skeletal muscle. Physiol Rev. 2009;81:209-37.

14. Lundberg JO, Weitzberg E. NO-synthase independent $\mathrm{NO}$ generation in mammals. Biochem Biophys Res Commun. 2010;396:39-45.

15. Potter $L$, Angove $H$, Richardson D, Cole J. Nitrate reduction in the periplasm of gram-negative bacteria. Adv Microb Physiol. 2001;45:51-112.

16. Lundberg JO, Weitzberg E, Gladwin MT. The nitrate-nitrite-nitric oxide pathway in physiology and therapeutics. Nat Rev Drug Discov. 2008;7:156-67.

17. Raat NJ, Shiva S, Gladwin MT. Effects of nitrite on modulating ROS generation following ischemia and reperfusion. Adv Drug Deliv. 2009;61:339-50.

18. Lundberg JO, Govoni M. Inorganic nitrate is a possible source for systemic generation of nitric oxide. Free Radic Biol Med. 2004;37:395-400.

19. Larsen FJ, Ekblom B, Lundberg JO, Weitzberg E. Effects of dietary nitrate on oxygen cost during exercise. Acta Physiol. 2007;191:59-66.

20. Ferguson SK, Hirai DM, Copp SW, Holdsworth CT, Allen JD, Jones AM, et al. Impact of dietary nitrate supplementation via beetroot juice on exercising muscle vascular control in rats. J Physiol. 2013;591:547-57.

21. Ignarro $\sqcup$, Adams JB, Horowitz PM. Activation of soluble guanylate cyclase by NOhemoproteins involves NO-heme exchange. J Biol Chem. 1986;261:4997-5002.

22. Furchgott R, Jothianandan D. Endothelium-dependent and -independent vasodilation involving cyclic GMP: relaxation induced by nitric oxide, carbon monoxide and light. Blood Vessels. 1991;28:52-61.

23. Erzurum SC, Ghosh S, Janocha AJ, Xu W, Bauer S, Bryan NS, et al. Higher blood flow and circulating NO products offset high-altitude hypoxia among Tibetans. Proc Natl Acad Sci U S A. 2007;104:17593-8.

24. Puype J, Ramaekers M, Thienen R, Deldicque L, Hespel P. No effect of dietary nitrate supplementation on endurance training in hypoxia. Scand Med Sci Sports. 2015;25:234-41.
25. Tong L, Heim RA, Wu S. Nitric oxide: a regulator of eukaryotic initiation factor 2, kinases. Free Radic Biol Med. 2011;50:1717-25.

26. Dejam A, Hunter C, Schechter A, Gladwin M. Emerging role of nitrite in human biology. Blood Cells Mol Dis. 2004;32:423-9.

27. Pinna M, Roberto S, Milia R, Maronquiu E, Olla S, Loi A. Effect of beetroot juice supplementation on aerobic response during swimming. Nutrients. 2014;6:605-15.

28. Handzlik L, Gleeson M. Likely additive Ergogenic effects of combined Preexercise dietary nitrate and caffeine ingestion in trained cyclists. ISRN Nutr. 2013:396581. https://doi.org/10.5402/2013/396581.

29. Boorsma RK, Whitfield SL. Beetroot juice supplementation does not improve performance of elite 1500-m runners. Med Sci Sports Exerc. 2014;46:2326-34.

30. Arnold J, James $L$, Jones T, Wylie L, Macdonald J. Beetroot juice does not enhance altitude running performance in well-trained athletes. Appl Physiol Nutr Metab. 2015;40:590-5.

31. MacLeod KE, Nugent SF, Barr S, Khoele MS, Sporer BC, Maclnnis MJ. Acute beetroot juice supplementation does not improve cycling performance in Normoxia or moderate hypoxia. Int J Sport Nutr Exerc Metab. 2015;25:359-66.

32. Vanhatalo A, Bailey SJ, Blackwell JR, DiMenna FJ, Pavey TG, Wilkerson DP, et al. Acute and chronic effects of dietary nitrate supplementation on blood pressure and the physiological responses to moderate-intensity and incremental exercise. Am J Physiol Regul Integr Comp Physiol. 2010;299:1121-31.

33. Lansley KE, Winyard PG, Bailey SJ, Vanhatalo A, Wilkerson DP, Blackwell JR, et al. Acute dietary nitrate supplementation improves cycling time trial performance. Med Sci Sports Exerc. 2011;43:1125-31.

34. Cermak N, Gibala M, Van Loon J. Nitrate Supplementation's improvement of 10-km time-trial performance in trained cyclists. Int J Sport Nutr Exerc Metab. 2012;22:64-71.

35. Wilkerson DP, Hayward GM, Bailey SJ, Vanhatalo A, Blackwell JR, Jones AM. Influence of acute dietary nitrate supplementation on 50 mile time trial performance in well-trained cyclists. Eur J Appl Physiol. 2012;112:4127-34.

36. Breese BC, McNarry MA, Marwood S, Blackwell JR, Bailey SJ, Jones AM. Beetroot juice supplementation speeds $\mathrm{O}_{2}$ uptake kinetics and improves exercise tolerance during severe-intensity exercise initiated from an elevated metabolic rate. Am J Physiol Regul Integr Comp Physiol. 2013;305:1441-50.

37. Kelly J, Vanhatalo A, Wilkerson D, Wylie L, Jones AM. Effects of nitrate on the power-duration relationship for severe-intensity exercise. Med Sci Sports Exerc. 2013;45:1798-806.

38. Muggeridge DJ, Howe CF, Spendiff O, Pedlar C, James PE, Easton C. The effects of a single dose of concentrated beetroot juice on performance in trained Flatwater kayakers. Int J Sport Nutr Exerc Metab. 2013;23:498-506.

39. Kelly J, Vanhatalo A, Bailey SJ, Wylie LJ, Tucker C, List S, et al. Dietary nitrate supplementation: effects on plasma nitrite and pulmonary $\mathrm{O}_{2}$ uptake dynamics during exercise in hypoxia and normoxia. Am J Physiol Regul Integr Comp Physiol. 2014;307:920-30.

40. Lane S, Hawley J, Desbrow B, Jones AM, Blackwell J, Ross ML. Single and combined effects of beetroot juice and caffeine supplementation on cycling time trial performance. Appl Physiol Nutr Metab. 2014;39:1050-7.

41. Muggeridge DJ, Howe C, Spendiff O, Pedlar C, James P, Easton C. A single dose of beetroot juice enhances cycling performance in simulated altitude. Med Sci Sports Exerc. 2014;46:143-50.

42. Thompson K, Turnerb L, Prichardb J, Doddb F, Kennedyb D, Haskellb C, et al. Influence of dietary nitrate supplementation on physiological and cognitive responses to incremental cycle exercise. Respir Physiol Neurobiol. 2014;193:11-20.

43. Glaister M, Pattison JR, Muniz-Pumares D, Patterson SD, Foley P. Effects of dietary nitrate, caffeine, and their combination on 20-km cycling time trial performance. J Strength Cond Res. 2015;29:165-74.

44. Peeling $P, C o x G$, Bullock N, Burke L. Beetroot juice improves on-water $500 \mathrm{M}$ time-trial performance, and laboratory-based paddling economy in national and international-level kayak athletes. Int J Sport Nutr Exerc Metab. 2015;25:278-84.

45. Whitfield J, Ludzki A, Heigenhauser G, Senden S, Verdijk L, Van L, et al. Beetroot juice supplementation reduces whole body oxygen consumption but does not improve indices of mitochondrial efficiency in human skeletal muscle. J Physiol. 2016;594:421-35.

46. Bescós R, Sureda A, Tur JA, Pons A. The effect of nitric-oxide-related supplements on human performance. Sports Med. 2012;42:1-19.

47. Hoon MW, Johnson NA, Chapman PG, Burke LM. The effect of nitrate supplementation on exercise performance in healthy individuals: a systematic review and meta-analysis. Int J Sport Nutr Exerc Metab. 2013;23:522-32

48. Clements WT, Lee SR, Bloomer RJ. Nitrate ingestion: a review of the health and physical performance effects. Nutrients. 2014;6:5224-64. 
49. Pawlak-Chaouch M, Boissiere J, Gamelin FX, Cuvelier G, Berthoin S, Aucouturier J. Effect of dietary nitrate supplementation on metabolic rate during rest and exercise in human: a systematic review and a meta-analysis. Nitric Oxide. 2016:53:65-76.

50. Domínguez R, Cuenca E, Maté-Muñoz JL, García-Fernández P, Serra-Paya N, Estevan $M C$, et al. Effects of beetroot juice supplementation on cardiorespiratory endurance in athletes. A systematic review Nutrients. 2017;9:1.

51. McMahon NF, Leveritt MD, Pavey TG. The effect of dietary nitrate supplementation on endurance exercise performance in healthy adults: a systematic review and meta-analysis. Sports Med. 2017:47:735-56.

52. Hernández A, Schiffer TA, Ivarsson N, Cheng AJ, Bruton JD, Lundberg JO, et al. Dietary nitrate increases tetanic [Ca2+]i and contractile force in mouse fasttwitch muscle. J Physiol. 2012;590:3575-83.

53. Martin K, Smee D, Thompson KG, Rattray B. No improvement of repeated-Sprint performance with dietary nitrate. Int J Sports Physiol Perform. 2014;9:845-50.

54. Aucouturier J, Boissiere J, Pawlak-Chaouch M, Cuvelier G, Gamelin FX. Effect of dietary nitrate supplementation on tolerance to supramaximal intensity intermittent exercise. Nitric Oxide. 2015;49:16-25.

55. Buck CL, Henry T, Guelfi K, Dawson B, McNaughton LR, Wallman K. Effects of sodium phosphate and beetroot juice supplementation on repeated-sprint ability in females. Eur J Appl Physiol. 2015;115:2205-13.

56. Thompson C, Wylie LJ, Fulford J, Kelly J, Black MI, McDonagh STJ, et al. Dietary nitrate improves sprint performance and cognitive function during prolonged intermittent exercise. Eur J Appl Physiol. 2015;115:1825-34.

57. Clifford T, Berntzen B, Davison GW, West DJ, Howatson G, Stevenson EJ. Effects of beetroot juice on recovery of muscle function and performance between bouts of repeated Sprint exercise. Nutrients. 2016;8:506.

58. Mosher SL, Sparks SA, Williams EL, Bentley DJ, McNaughton LR. Ingestion of a nitric oxide enhancing supplement improves resistance exercise performance. J Strength Cond Res. 2016;30:3520-4.

59. Rimer EG, Peterson LR, Coggan AR, Martin JC. Increase in maximal cycling power with acute dietary nitrate supplementation. Int J Sports Physiol Perform. 2016;11:715-20

60. Wylie LJ, Mohr M, Krustrup P, Jackman SR, Ermidis G, Kelly J, et al. Dietary nitrate supplementation improves team sport-specific intense intermittent exercise performance. Eur J Appl Physiol. 2013;113:1673-84

61. Domínguez R, Garnacho-Castaño MV, Maté-Muñoz JL. Efectos del entrenamiento contra resistencias o resistance training en diversas patologías. Nutr Hosp. 2016;33:719-33.

62. Ratamess NA, Albar BA, Evetoch TK, Housh TJ, Kibler WB, Kraemer WJ, et al Special communication. American College of Sports Medicine position stand: progression models in resistance training for healthy adults. Med Sci Sports Exerc. 2009;41:687-708.

63. Garnacho-Castaño MV, Domínguez R, Maté-Muñoz JL. Understanding the meaning of the lactate threshold in resistance exercises. Int J Sports Med. 2015;36:371-7.

64. Garnacho-Castaño MV, Domínguez R, Ruiz-Solano P, Maté-Muñoz JL. Acute physiological and mechanical responses during resistance exercise executed at the lactate threshold workload. J Strength Cond Res. 2015;29:2867-73.

65. Carr BM, Webster MJ, Boyd JC, Hudson GM, Scheett TP. Sodium bicarbonate supplementation improves hypertrophy-type resistance exercise performance. Eur J Appl Physiol. 2013;113:743-52.

66. Phillips SM. Nutritional supplements in support of resistance exercise to counter age-related sarcopenia. Adv Nutr. 2015;6:452-60.

67. Tomlin DL, Wenger HA. The relationship between aerobic fitness and recovery from high intensity intermittent exercise. Sports Med. 2001;31:1-11.

68. Vanhatalo A, Fulford J, Bailey SJ, Blackwell JR, Winyard PG, Jones AM. Dietary nitrate reduces muscle metabolic perturbation and improves exercise tolerance in hypoxia. J Physiol. 2011;589:5517-28.

69. Bloomer JR, Farney TM, Trepanowski JF, McCarthy CG, Canale RE, Schilling BK. Research article comparison of preworkout nitric oxide stimulating dietary supplements on skeletal muscle oxygen saturation, blood nitrate/ nitrite, lipid peroxidation, and upper body exercise performance in resistance trained men. J Int Soc Sports Nutr. 2010;7:1-15.

70. Spencer M, Bishop D, Dawson B, Goodman C. Physiological and metabolic responses of repeated-sprint activities. Sports Med. 2005:35:1025-44.

71. O'Donoghue P, Ingram B. A notational analysis of elite tennis strategy. J Sport Sci. 2001;19:107-15.

72. Felippe LC, Lopes-Silva JP, Bertuzzi R, McGinley C, Lima-Silva AE. Separate and combined effects of caffeine and sodium-bicarbonate intake on judo performance. Int J Sports Physiol Perform. 2016;11:221-6.
73. Mujika I. Nutrition in team sports. Ann Nutr Metab. 2010;57:26-35.

74. Fitzsimons $\mathrm{M}$, Dawson BT, Ward D, Wilkinson A. Cycling and running tests of repeated sprint ability. Aust J Sci Med Sport. 1993;25:82-7.

75. Krustrup P, Mohr M, Steensberg A, Bencke J, Kjaer M, Bangsbo J. Muscle and blood metabolites during a soccer game: implications for sprint performance. Med Sci Sports Exerc. 2006;38:1165-74.

76. Krustrup P, Söderlund K, Relu MU, Ferguson RA, Bangsbo J. Heterogeneous recruitment of quadriceps muscle portions and fibre types during moderate intensity knee-extensor exercise: effect of thigh occlusion. Scand J Med Sci Sports. 2009;19:576-84.

77. Lucía A, Sánchez O, Carvajal A, Chicharro JL. Analysis of the aerobic-anaerobic transition in elite cyclists during incremental exercise with the use of electromyography. Br J Sports Med. 1999;33:178-85.

78. Syrotuik DG, Bell GJ. Acute creatine monohydrate supplementation: a descriptive physiological profile of responders vs. nonresponders. J Strength Cond Res. 2004;18:610-7

79. Volek JS, Kraemer WJ. Creatine supplementation: its effect on human muscular performance and body composition. J Strength Cond Res. 1996;10:200-10.

80. Kendrick IP, Kim HJ, Harris RC, Kim CK, Dang VH, Lam TQ, et al. The effect of 4 weeks b-alanine supplementation and isokinetic training on carnosine concentrations in type I and II human skeletal muscle fibres. Eur J Appl Physiol. 2009;106:131-8.

81. Fulford J, Winyard PG, Vanhatalo A, Bailey SJ, Blackwell JR, Jones AM. Influence of dietary nitrate supplementation on human skeletal muscle metabolism and force production during maximum voluntary contractions. Pflugers Arch. 2013;465:517-28

82. Wallimann T, Tokarska-Schlattner M, Schlattner U. The creatine kinase system and pleiotropic effects of creatine. Amino Acids. 2011;40:1271-96.

83. Trivedi $\mathrm{B}$, Daniforth $\mathrm{WH}$. Effect of $\mathrm{pH}$ on the kinetics of frog muscle phosphofructokinase. J Biol Chem. 1966:241:4110-2.

84. Sahlin K, Harris RC. The creatine kinase reaction: a simple reaction with functional complexity. Amino Acids. 2011:40:1363-7.

85. Hobson RM, Saunders B, Ball G, Harris RC, Sale C. Effects of beta-alanine supplementation on exercise performance: a review by meta-analysis. Amino Acids. 2012;43:25-37.

86. Messonier L, Kristensen M, Juel C, Denis C. Importance of $\mathrm{pH}$ regulation and lactate/ $\mathrm{H}+$ transport capacity for work production during supramaximal exercise in humans. J Appl Physiol. 2007:102:1936-44.

87. Sterlingwerff T, Decombaz J, Harris RC, Boesch C. Optimizing human in vivo dosing and delivery of $ß$-alanine supplements for muscle carnosine synthesis. Amino Acids. 2012;43:57-65.

88. Harris RC, Tallon MJ, Dunnett M, Boobis L, Coakley J, Kim HJ, et al. The absorption of orally supplied beta-alanine and its effect on muscle carnosine synthesis in human vastus lateralis. Amino Acids. 2006;30:279-89.

89. Requena B, Zabala M, Padial P, Feriche B. Sodium bicarbonate and sodium citrate: ergogenic aids? J Strength Cond Res. 2005;19:213-24.

90. Domínguez R, Lougedo JH, Maté-Muñoz JL, Garnacho-Castaño MV. Efectos de la suplementación con $\beta$-alanina sobre el rendimiento deportivo. Nutr Hosp. 2015:31:155-69.

91. Tobias G, Benatti FB, De Salles V, Roschel H, Gualano B, Sale C, et al. Additive effects of beta-alanine and sodium bicarbonate on upper-body intermittent performance. Amino Acids. 2013;45:309-17.

92. Gray SR, Söderlund K, Ferguson RA. ATP and phosphocreatine utilization in single human muscle fibres during the development of maximal power output at elevated muscle temperatures. J Sports Sci. 2008;26:701-7.

93. Poole DS, Copp SW, Hirai DM, Musch TI. Dynamics of muscle microcirculatory and blood-myocyte O(2) flux during contractions. Acta Physiol. 2011;202:293-310.

94. Bogdanis GC, Nevill ME, Lakomy HK, Graham CM, Louis G. Effects of active recovery on power output during repeated maximal sprint cycling. Eur J Appl Physiol Occup Physiol. 1996;74:461-9.

95. Haseler $\sqcup$, Hogan MC, Richardson RS. Skeletal muscle phosphocreatine recovery in exercise-trained humans is dependent on O2 availability. J Appl Physiol. 1999;86:2013-8.

96. Martin JC, Brown NA, Anderson FC, Spirduso WW. A governing relationship for repetitive muscular contraction. J Biomech. 2000:33:969-74.

97. Marechal G, Beckers-Bleukx G. Effect of nitric oxide on the maximal velocity of shortening of a mouse skeletal muscle. Pflugers Arch. 1998:436:906-13.

98. Marechal G, Gailly P. Effects of nitric oxide on the contraction of skeletal muscle. Cell Mol Life Sci. 1999:55:1088-102.

99. Kramer SJ, Baur DA, Spicer MT, Vukovich MD, Ormsbee MJ. The effect of six days of dietary nitrate supplementation on performance in trained CrossFit athletes. J Int Soc Sports Nutr. 2016;13:39. 
100. Bobbert MF, Van Soest AJ. Why do people jump the way they do? Exerc Sport Sci Rev. 2001;29:95-102.

101. Rodacki ALF, Fowler NE, Bennett SJ. Multi-segment coordination: fatigue effects. Med Sci Sports Exerc. 2001;33:1157-67.

102. Sánchez-Medina L, González-Badillo JJ. Velocity loss as an indicator of neuromuscular fatigue during resistance training. Med Sci Sports Exerc. 2011;43:1725-34.

103. Rodacki AL, Fowler NE, Bennett SJ. Vertical jump coordination: fatigue effects. Med Sci Sports Exerc. 2002;34:105-16.

104. Mosteiro-Muñoz F, Domínguez R. Effects of inertial overload resistance training on muscle function. Rev Int Med Cienc Act Fís Deporte. 2017;In press.

Submit your next manuscript to BioMed Central and we will help you at every step:

- We accept pre-submission inquiries

- Our selector tool helps you to find the most relevant journal

- We provide round the clock customer support

- Convenient online submission

- Thorough peer review

- Inclusion in PubMed and all major indexing services

- Maximum visibility for your research

Submit your manuscript at www.biomedcentral.com/submit
Biomed Central 